\title{
Smoking and other health related behaviour in the social and environmental context
}

\author{
Stuart Logan, Nick Spencer
}

There has recently been considerable emphasis in sociomedical research on the link between health related behaviours and adverse outcomes, a link which is seen to 'explain' the effects of social and environmental circumstances. $^{1-3}$ A Royal College of Physicians working party, for example, concluded that parental smoking was the most important single preventable cause of ill health in childhood. ${ }^{4}$

This paper reviews the relationship between social and environmental circumstances, health related behaviour, and adverse health outcomes and re-examines the link between adverse pregnancy and early childhood health outcomes and parental health related behaviours, particularly smoking. We will argue that the magnitude of the effects of health behaviours on child health has sometimes been overestimated and the nature of the link between social and environmental circumstances and health has frequently been misinterpreted. We suggest that this is the result of flaws in the interpretation of data in a number of key studies and a confusion between proximal and distal causes of ill health. In particular, we believe that parental smoking, seen by some as 'explaining' the major social class gradients in child health, ${ }^{5}$ has less direct effect than suggested and should be seen as only one factor within a complex constellation of adverse influences strongly correlated with social and environmental circumstances.

The association between social and environmental circumstances, health related behaviour, and adverse health outcomes

Social and environmental circumstances is used in this discussion to denote a constellation of

Correspondence to: Dr Logan. factors, including income, occupation, housing, and local environment, affecting individuals which are determined, in large part, by the structure of society.

Diet and smoking are strongly correlated with social and environmental circumstances. Low income families consume more animal fat, potatoes, sugar, and preserves and less fruit and fresh vegetables than high income families. ${ }^{6}$ Smoking, particularly among women, has been increasingly associated with material deprivation since the $1950 \mathrm{~s},{ }^{7-9}$ and smoking in pregnancy is consistently correlated with material deprivation in the UK, ${ }^{10} 11$ the USA, ${ }^{12}$ and northern Europe ${ }^{913}$ (see table 1).

Within each social group, women smoking during pregnancy tend to be the least educated, the least likely to own their own home, and the most likely to have lower incomes. ${ }^{11}$ The lower the income of the mother, the more likely she is to smoke more and the less likely she is to give up during pregnancy. 14

Adverse pregnancy and childhood outcomes are also strongly correlated with measures of poor social and environmental circumstances ${ }^{1516}$ and it is changes in social and environmental circumstances, rather than medical advances or changes in behaviour, have been the main determinants of health improvements in developed countries in the last century. ${ }^{17-19}$

Clearly, both health related behaviours and adverse health outcomes are closely linked with social and environmental circumstances ${ }^{20}$ and disentangling their effects in the analysis of research findings is fraught with problems of confounding. ${ }^{21}$

\section{Smoking and the fetus and young child}

Parental smoking has been implicated as a causal factor in spontaneous abortion, ${ }^{22}$ perinatal death, ${ }^{23}$ low birth weight, ${ }^{24}$ sudden unexpected death in infancy, ${ }^{5}$ and in impaired growth $^{26}$ and intellectual development. ${ }^{27}$

The pathophysiological evidence suggests that maternal smoking exerts a direct effect on the fetus, ${ }^{28} 29$ in part mediated by an effect on the placental circulation. Passive smoking in early childhood is thought to have direct pathophysiological effects, particularly on the infant lung. ${ }^{4}$

Epidemiological studies show some inconsistencies. A study from Shanghai, in which no
Access to car/van

Tried to give up smoking in

pregnancy

$\star \star \star p<0.0001$.
Sample of working class mothers $(n=905)$

\begin{tabular}{llll}
$\begin{array}{l}\text { Never smoked } \\
(n=307)\end{array}$ & $\begin{array}{l}\text { Ex-smokers } \\
(n=126)\end{array}$ & $\begin{array}{l}\text { Light smokers } \\
(n=312)\end{array}$ & $\begin{array}{l}\text { Heavy smokers } \\
(n=160)\end{array}$ \\
\hline 21 & 25 & 39 & $51^{\star \star \star}$ \\
64 & 56 & 43 & $26^{\star \star \star}$ \\
71 & 67 & 53 & $51^{\star \star \star}$ \\
- & - & 47 & 29
\end{tabular}


mothers smoked, concluded that passive smoking in early infancy related to paternal smoking was a major determinant of respiratory illness with evidence of a dose-response effect. ${ }^{30}$ However, studies in the UK, the USA, and New Zealand have shown no independent effect of paternal smoking. ${ }^{31-34}$ They report an association of respiratory admissions in infancy with maternal smoking in pregnancy and postulate a direct effect on the fetus rather than later passive smoking.

\section{Problems in the interpretation of data related to social and environmental circumstances and health behaviour} In the UK, a number of studies have documented the association between health behaviours and adverse outcomes in infants and young children, results which have been interpreted as demonstrating a causal link. Reexamination of these studies reveals a number of flaws in the interpretation of the data. These flaws fall into four main categories.

\section{(1) INADEQUATE CLASSIFICATION OF SOCIAL} AND ENVIRONMENTAL CIRCUMSTANCES A common problem is the inadequate classification of factors making up the social and environmental circumstances. Most UK studies use the registrar general's classification of social class, based on the occupation of the head of the household. This does not adequately reflect health inequalities, particularly in studies of maternal and child health. ${ }^{35}$ Intraclass variation in health outcomes is known to be large. ${ }^{36}$ The exclusion from routine health data of children whose parents are classified as 'unoccupied', has been shown to produce a misleading picture of inequalities in child health ${ }^{37}$ as they have even higher mortality rates than children in social class $\mathrm{V}$. The effect of this inadequate classification is to blur the extent of differences between social groups.

\section{(2) INSUFFICIENT ALLOWANCE FOR RESIDUAL CONFOUNDING}

The potential for residual confounding arises when the exposure of interest and the potential confounders are closely correlated. The degree to which a potential confounder can be controlled for in an analysis depends on the precision with which it can be measured for individual subjects. ${ }^{38}$ The more closely the exposure is correlated with the potential confounder, the greater the impact of the residual confounding on the analysis. ${ }^{36}$

Evidence from adults suggests that as much as $30 \%$ of the apparent independent effect of smoking may be due to inadequate classification of social factors. ${ }^{36}$ The extent to which smoking acts as a surrogate measure of social and environmental circumstances within a particular analysis will depend on two factors. Firstly, how precise is the classification of social and environmental circumstances. In many studies, it is dichotomised into 'non-manual' and 'manual' groups on the basis of occupation: as these groups are not homogeneous, intraclass variations in outcome are likely to be large. Any factor acting as a surrogate measure of this variation will appear to have a substantial independent effect in a multivariate analysis. Rates of smoking in women vary with income within each social class ${ }^{11}$ and therefore smoking may act as a measure of variation within class.

Secondly, although social and environmental circumstances are associated with many outcomes, there are few data to clarify which particular factors are important for a particular outcome. Clearly, social and environmental circumstances do not 'cause' adverse health outcomes, they are simply markers for an increased risk of some particular constellation of causes. The measure of social and environmental circumstances chosen for the analysis may not be a valid measure of those factors which are important for the outcome of interest. This may increase the apparent effects of surrogate measures of social and environmental circumstances, such as maternal smoking, in the analysis.

In epidemiological studies, a dose-response relationship is regarded as strong evidence of causality. Where a dose-response relationship exists, for the association to be due to confounding, the confounder must also have a dose-response relationship with the outcome and be closely correlated with the exposure. The apparent dose-response relationship of smoking to adverse fetal and early childhood outcomes has been used to substantiate the view that the relationship is causal. ${ }^{431}$ However, there is also a dose-response relationship between maternal smoking in pregnancy and deprivation $^{14} 39$ suggesting that the association may, in part, reflect confounding by social and environmental circumstances related factors.

\section{(3) USE OF INAPPROPRIATELY ADJUSTED}

\section{OUTCOME MEASURES}

In some widely quoted studies, the authors have carried out the analysis in two stages: first adjusting the outcome variable to take account of potential confounders and then examining the effects of social and environmental circumstance variables on the adjusted variable. This is a superficially attractive method but, where the variables for which the outcome is adjusted are correlated with social and environmental circumstances, this will reduce the apparent effect of social and environmental circumstance variables in the main analysis. The correct approach requires that both the outcome and the independent variables be 'adjusted' for the effects of the confounder.

This phenomenon is illustrated by a study of the height of schoolchildren which concluded that observed social class variation in children's height was the result of biological variation in the mothers. ${ }^{40}$ The outcome measure used in the analysis was a height score adjusted for maternal height and the child's birth weight. After these adjustments, social class variations in height no longer reached conventional levels of statistical significance. 
However, maternal height and birth weight reflect both biological and social factors so that the initial adjustment inevitably reduces the apparent effect of social and environmental circumstances.

Similarly, Brooke et al in assessing the effects of smoking and social factors on birth weight, use as their outcome measure birth weight corrected for gestational age and maternal height. ${ }^{24}$ Here again, adjusting for a variable (maternal height) closely correlated with social and environmental circumstances, is likely to diminish their apparent effect.

\section{(4) BEHAVIOUR AS THE PRIMARY RESEARCH} FOCUS

The preoccupation with behavioural influences may also affect the interpretation of results. Harlap and Davies reported that parental smoking has an effect, independent of social group, on early childhood admission with bronchitis and pneumonia. ${ }^{41}$ An alternative interpretation of the figures presented in the paper might lead to a different emphasis (see table 2).

Although there is a small increased relative risk of admission for pneumonia and bronchitis among the infants of smokers, the risks associated with low social group are far greater in the infants of both smokers and nonsmokers, a finding not discussed by the authors.

\section{Other reasons to doubt that smoking explains all the social and environmental circumstance differences in adverse outcomes}

There are other reasons to doubt the contention that smoking 'explains' social and environmental circumstance differences in adverse outcomes.

Smoking among women in northern Europe is a relatively recent phenomenon. ${ }^{79}$ Before 1940, few women smoked. Since the 1950s when equal numbers of women from different social groups smoked, smoking among women and in pregnancy has become increasingly associated with material deprivation. ${ }^{7}$ However, the social class gradient in childhood mortality and morbidity has remained unchanged throughout this period. Further evidence comes from countries with different social patterns of smoking among women. In Spain and Greece, for example, smoking among women is not associated with deprivation. In $1987,37 \cdot 7 \%$ of women in highest income families in Spain compared

Table 2 Hospital admission in infancy by smoking and social group (reanalysis of data from Harlap and Davies, $1974^{41}$ ); values are relative risk (95\% confidence limits)

\begin{tabular}{lll}
\hline & $\begin{array}{l}\text { Bronchitis and } \\
\text { pneumonia admissions }\end{array}$ & $\begin{array}{l}\text { Other } \\
\text { admissions }\end{array}$ \\
\hline $\begin{array}{l}\text { Smokers } v \text { non-smokers } \\
\text { Low } v \text { high and middle social group: } \\
\text { (a) Whole sample }\end{array}$ & $1 \cdot 38(1 \cdot 16<\mathrm{OR}<1 \cdot 64)$ & $1 \cdot 11(0 \cdot 93<\mathrm{OR}<1 \cdot 33)$ \\
$\begin{array}{l}\text { (b) Non-smokers only } \\
\begin{array}{l}\text { Lw } v \text { high social group: } \\
\text { (a) Whole sample }\end{array}\end{array}$ & $2 \cdot 02(1 \cdot 80<\mathrm{OR}<2 \cdot 27)$ & $1 \cdot 86(1 \cdot 70<\mathrm{OR}<2 \cdot 03)$ \\
(b) Non-smokers only & $2 \cdot 27(1.97<\mathrm{OR}<2 \cdot 61)$ & $1 \cdot 90(1 \cdot 73<\mathrm{OR}<2 \cdot 08)$ \\
& $3.45(2 \cdot 87<\mathrm{OR}<4 \cdot 16)$ & $2 \cdot 37(2 \cdot 09<\mathrm{OR}<2 \cdot 69)$ \\
& $4 \cdot 11(3 \cdot 29<\mathrm{OR}<5 \cdot 15)$ & $2 \cdot 75(2 \cdot 40<\mathrm{OR}<3 \cdot 15)$
\end{tabular}

$\mathrm{OR}=$ odds ratio. with $7 \%$ in the lowest income group ${ }^{42}$ and in 1986 in the Greek region of Ioannina, $21 \%$ of 'upper class' women smoked in pregnancy compared with $10 \%$ of 'lower class' women. ${ }^{43}$ However, the pattern of adverse outcomes in pregnancy shows a similar correlation with social and environmental circumstances to that seen in the UK. ${ }^{44}$

\section{Conclusions}

It - seems clear that parental smoking is harmful, although the magnitude of its effect may be smaller than sometimes suggested. However, smoking and other behaviours detrimental to health must be seen within a social and historical context. Individuals are not 'free choosing actors' and their behaviour is determined, at least in part, by their social and environmental circumstances.

Smoking might better be regarded as a 'proximal' cause. ${ }^{17}$ 'Proximal' causes such as infectious or toxic agents are themselves subject to 'causes of causes' which are the determinants of exposure to these agents. Smoking may act as the 'proximal' cause, directly harming the fetus, but is itself caused by factors in the social and environmental circumstances. The complexity of the relationship between social and environmental circumstances, health related behaviours, and adverse outcomes cannot be resolved by the search for single causative agents. As Rutter points out, in order to begin to understand causal complexity 'it is necessary to examine distal causal relationships in the form of chains and of linked sequences involving several different, relatively short-term effects or operations' ( $\mathrm{p} 2) .{ }^{45}$

Health promotion programmes sensitive to social context ${ }^{46}$ avoid 'victim blaming' and acknowledge that it is not enough to exhort mothers to 'stop smoking before and during pregnancy because this will harm your baby' (p 99)..$^{5}$ Mothers know that smoking can harm themselves and their babies and the vast majority want to give up. ${ }^{12}$ Their choice is limited by their social circumstances, and failure to recognise this has ensured the failure of health promotion initiatives aimed at smoking reduction during pregnancy. ${ }^{39}$

There are limitations in the techniques available to control for confounding in multivariate analysis and results must be interpreted with caution. Misinterpretation can lead to overemphasis of the role of single factors, diverting attention from complex pathways. While health related behaviours may be a 'proximal' cause of ill health, there is a duty on researchers, health promoters, and health policy makers to take account of the complex causal pathways in which these 'proximal' causes lie.

1 McIntyre $S$. The patterning of health by social position in contemporary Britain: directions for sociological research. Soc Sci Med 1986; 23: 393 415 .

2 Blane D. An assessment of the Black report's 'explanations' of health inequalities. Sociology of Health and Illness 1985; 7: 423-45.

3 Department of Health. The health of the nation. London: HMSO, 1992 
4 Royal College of Physicians of London. Smoking and the young: report of a working party of the Royal College of Physicians. London: Royal College of Physicians of London, 1992

5 Butler NR, Golding J, eds. From birth to five: a study of the health and behaviour of a national cohort. Oxford: Pergamon, 1986

6 Ministry of Agriculture, Fisheries and Food. Household food consumption and expenditure. London: HMSO, 1991.

7 Graham H. Women's smoking and family health. Soc $S c i$ Med 1987; 25: 47-56.

8 British Medical Association. Smoking and pregnancy: survey of general practitioners. London: Economic Research Unit, of general practit

9 Chollat-Traquet C. Women and tobacco. Geneva: World Health Organisation, 1992.

10 Graham H. Women's smoking: government targets and social trends. Health Visitor 1993; 66: 80-2.

11 Haste F, Brooke O, Anderson H, Bland J, Peacock J. Social determinants of nutrient intake in smokers and nonsmokers during pregnancy. $\mathcal{F}$ Epidemiol Community Health 1990; 44: 205-9.

12 Pierce JP. International comparisons of trends in cigarette smoking prevalence. Am f Public Health 1989 79: $152-7$

13 Rantakallio P. Social background of mothers who smoke during pregnancy and influence of these factors on the offspring. Soc Sci Med 1979; 13A: 423-9.

14 Graham H. Smoking among working class mothers. Primary Health Care 1993; 3 (2): 15-6.

15 Townsend $\mathrm{P}$, Davidson $\mathrm{N}$, Whitehead $\mathrm{M}$. Inequalities in health: the Black report and the health divide. Harmondsworth: Penguin, 1992.

16 Spencer NJ. Poverty and child health: an annotation. Children and Society 1990; 4: 352-64.

17 Rose G. The strategy of preventive medicine. Oxford: Oxford Medical Publications, 1992.

18 McKeown $\mathrm{T}$. The role of medicine: dream, mirage or nemesis? London: The Nuffield Hospitals Trust, 1976.

19 Szreter S. The importance of social intervention in Britain's morality decline c 1850-1914: a reinterpretation. (Discussion paper No 121.) London: Centre for Economic Policy Research, 1986 .

20 Blaxter $M$. Health services as a defence against the consequences of poverty in industrialised societies. Soc Sci Med 1983; 17: 1139-48.

21 Davey-Smith G, Shipley MJ. Confounding of occupation and smoking: its magnitude and consequences. Soc $\mathrm{Sci}$ Med 1991; 32: 1297-1300.

22 Himmelberger D, Brown B, Cohen E. Cigarette smoking during pregnancy and the occurrence of spontaneous abortion and congenital abnormality. $A m \stackrel{f}{\mathcal{J}}$ Epidemiol 1978; 108: 470-9.

23 Comstock GW, Shah FK, Meyer MB, Abby H. Low birth weight and neonatal mortality related to materna smoking and socio-economic status. Am $\mathcal{f}$ Obstet Gynecol 1971; 111: 53-9.

24 Brooke OG, Anderson HR, Bland JM, Peacock JL, Stewart C. Effect on birth weight of smoking, alcohol, caffeine, socio-economic factors and psychosocial stress. $B M \mathcal{J}$ 1989; 298: 795-801.

25 Haglund B, Cnattingius S. Cigarette smoking as a risk factor for sudden infant death syndrome: a population based study. Am F Public Health 1990; 80: 29-32.

26 Rona R, Chinn S, Florey C. Exposure to cigarette smoking and children's growth. Int f Epidemiol 1985; 14: 402-9.
27 Fogelman K. Smoking in pregnancy and subsequent development of the child. Child Care Health Dev 1980; 6: 233-49.

28 Burton GJ. The effects of maternal cigarette smoking on placental structure and function in mid- to late gestation. In: Poswillo D, Alberman E, eds. Effects of smoking on the fetus, neonate, and child. Oxford: Oxford Medical Publications, 1992: 60-72.

29 Symonds $\mathrm{E}$. The effect of smoking on oxygen transfer and placental circulation. In: Poswillo D, Alberman E, eds. Effects of smoking on the fetus, neonate and child. Oxford: Oxford Medical Publications, 1992: 73-80.

$30 \mathrm{Chen} \mathrm{Y}, \mathrm{Li} \mathrm{W}$, Yu S. Influence of passive smoking on admissions for respira

31 Evans J-A, Golding J. Parental smoking and respiratory problems in childhood. In: Poswillo D, Alberman E, eds. Effects of smoking on the fetus, neonate and child

32 Lucas A, Brooke O, Cole T, Morley R, Bamford M. Food and drug reactions, wheezing and eczema in preterm infants. Arch Dis Child 1990; 65: 411-5.

33 Tager I, Weiss S, Munoz A, Rosner B, Speizer F. Longitudinal study of the effects of maternal smoking on pulmonary function in children. $N$ Engl F Med 1983; 309: 699-702.

34 Fergusson DM, Horwood LJ, Shannon FT, Taylor B. Parental smoking and lower respiratory illness in the firs three years of life. $\mathcal{F}$ Epidemiol Community Health 1981; 35: $180-4$.

35 Oakley A, Rigby A, Hickey D. Women and children last? Class, health and the role of the maternal and child health services. European fournal of Public Health 1993; 3: 220-6.

36 Davey-Smith G, Phillips AN. Confounding in epidemiological studies: why 'independent' effects may not be all they ical studies: why 'independent'

37 Judge K, Benzeval M. Health inequalities: new concern about the children on single mothers. $B M F$ 1993; 306: 677-80.

38 Leon D. Failed or misleading adjustment for confounding. Lancet 1993; 342: 379-81.

39 Gillies PA, Madeley RJ, Power FL. Why do pregnant women smoke? Public Health 1989; 103: 337-43.

40 Gulliford M, Chinn S, Rona R. Social environment and height: England and Scotland, 1987 and 1988. Arch Dis Child 1991; 66: 235-40.

41 Harlap S, Davies A. Infant admissions to hospital and maternal smoking. Lancet 1974; i: 529-32.

42 Ministerio de Sanidad y Consumo, Spain. National smoking survey, 1987. Madrid, Spain: Ministerio de Sanidad y Consumo, 1987.

43 Griva E, Tsirka A, Lolis D, Lapatsanis P. Frequency of smoking in pregnant women. Proceedings of the 25th National Greek Paediatric Conference. Patra, 1987 (abstract No 54).

44 Armero MJ, Frau MJ, Colomer C. Health indicators for urban areas: geographic variation according to social
coherence. Gaceta Sanitaria (Spanish) 1991 (January/February); 22: 17-20.

45 Rutter $M$. Longitudinal data in the study of causal processes: some uses and some pitfalls. In: Rutter M, ed. Studies of psychosocial risk: the power of longitudinal data. Cambridge: European Science Foundation, Cambridge University Press, 1988: 1-28.

46 Blackburn C, Graham H. Smoking amongst working class mothers. (An information pack.) Coventry: Department of Applied Social Studies, University of Warwick, 1993. 